\section{EMBRYAIDDLE Aeronautical University}

SCHOLARLY COMMONS

\section{International Journal of Aviation,} Aeronautics, and Aerospace

\title{
Effect of chemical reactions on the fluidic thrust vectoring of an axisymmetric nozzle
}

\author{
Rachid CHOUICHA \\ Institut d'Aéronautique et des Etudes Spatiales, Université Saad Dahlab-Blida1, \\ rachidchouicha@hotmail.fr \\ Mohamed SELLAM \\ mohamed.sellam@univ-evry.fr \\ Said BERGHEUL \\ sarlbergheul@gmail.com
}

Follow this and additional works at: https://commons.erau.edu/ijaaa

Part of the Aerodynamics and Fluid Mechanics Commons, Aeronautical Vehicles Commons, Astrodynamics Commons, Other Aerospace Engineering Commons, Propulsion and Power Commons, Space Vehicles Commons, and the Systems Engineering and Multidisciplinary Design Optimization Commons

\section{Scholarly Commons Citation}

CHOUICHA, R., SELLAM, M., \& BERGHEUL, S. (2019). Effect of chemical reactions on the fluidic thrust vectoring of an axisymmetric nozzle. International Journal of Aviation, Aeronautics, and Aerospace, 6(5). https://doi.org/10.15394/ijaaa.2019.1377

This Article is brought to you for free and open access by the Journals at Scholarly Commons. It has been accepted for inclusion in International Journal of Aviation, Aeronautics, and Aerospace by an authorized administrator of Scholarly Commons. For more information, please contact commons@erau.edu. 


\section{Introduction}

The transverse injection of a fluid in a supersonic flow generates a complex flow involving asymmetric detachment due to an adverse pressure gradient, various interactions and reflections of shocks and vortex zones governing the mixture of flows downstream. Zones of high pressure upstream and low pressure downstream of the jet cause a natural inclination of the jet downstream of the flow.

The phenomenon of a secondary flow injection into the supersonic nozzles is largely documented in the literature. Analytical models (Mnafeg, Abichou, \& Beji, 2015; Sellam, Chpoun, Zmijanovic, \& Lago, 2012; Sellam, Zmijanovic, Leger, \& Chpoun, 2015) have been proposed for studying the performance of fluidic vectorization by identifying relating parameters such as: i) the height of the fluidic obstacle formed by the secondary injection ii) the flow separation line in front of the injector iii), and the forces applied on the wall of the nozzle.

In addition, experimental studies and numerical simulations were also carried out on the performance of the thrust vectoring (Deng, Kong, \& Kim, 2014; Ferlauto \& Marsilio, 2017; Jerin, Subanesh, Tharika, Subanesh, \& Naveen, 2013; Van Pelt, Neely, \& Young, 2015; Zmijanovic, Lago, Leger, Depussay, Sellam, \& Chpoun, 2013; Zmijanovic, Leger, Lago, Sellam, \& Chpoun, 2012, 2013). These studies mainly focused on the wall nozzle pressure distribution and force balance measurements, for several configurations involving injection position as well as the injection angle. The experimental investigations are too relevant but remain very expensive considering the complexity of the experimental devices necessary to achieve them.

The transverse injection of different gases in the main supersonic flow was also investigated by Sellam et al. (2015). Mainly, they found that the penetration height depends on the secondary jet mass-flow rate, rather than the thermodynamic properties of the secondary gas. The injecting gas species have a strong influence on the aerodynamic flow field and consequently their contribution to the vectoring performance.

In general, the published works within the field of fluidic thrust vectoring, are essentially based on the use of the perfect cold gas model with constant specific heat ratio. Hence, this assumption neglects the real behavior of the gas for flow temperatures higher than $1000 \mathrm{~K}^{\circ}$.

There are three main types of fluidic injection: counter-flow (Jun \& Hong, 2012; Mangin et al., 2006), coflow (Flamm, Deere, Mason, Berrier, \& Johnson, 2007), and shock vector control (Sellam et al., 2012). The investigations carried out here deals with the shock vector control which uses the injection of a secondary flow, downstream the throat, in the supersonic part of the nozzle.

The aim of the current study, is to investigate the performance of the fluidic thrust vectoring (FTV) by means of a sonic secondary injection through a circular orifice, according to conditions such as: NPR, SPR, and injector 
position as to separation criterion. We will be focused essentially on the effects of reacting gases related to high temperatures. It's well known that the temperature of the gas greatly affects the supersonic nozzle flow properties, such as boundary layer thickness and shock separation position. Therefore, one should expect an impact on the performance of the vectorization.

A comparative study between our results and those obtained by Zmijanovic et al. (2013), for cold flow configurations, is presented here. Globally, this comparison was very satisfying in view of the good agreement between the results.

\section{Nomenclature:}

$\begin{array}{ll}A & \text { Section } \\ F_{x} & \text { Axial effort } \\ F_{y} & \text { Normal effort } \\ h & \text { Fluidic obstacle height } \\ M & \text { Mach number } \\ \dot{m} & \text { Mass flow } \\ P, \mathrm{p} & \text { Total pressure and static pressure } \\ q & \text { Dynamic pressure } \\ \mathrm{V} & \text { Velocity vector } \\ \mathrm{X} & \text { Axial direction } \\ \mathrm{y} & \text { Normal direction } \\ \gamma & \text { Ration of specific heats } \\ \delta & \text { Thrust vector angle } \\ \rho & \text { Density } \\ \mathrm{C} & \text { Specific heat at constant pressure of mixture }(\mathrm{J} / \mathrm{Kg}-\mathrm{K}) . \\ \mathrm{H} & \text { Specific enthalpy of mixture }(\mathrm{J} / \mathrm{Kg}) . \\ \mathrm{S} & \text { Specific entropy of mixture }(\mathrm{J} / \mathrm{Kg}-\mathrm{K}) . \\ \mathrm{R} & \text { Universal gas constant }(\mathrm{J} / \mathrm{mole}-\mathrm{K}) . \\ \text { av } & \text { Conditions of flow downstream of the control volume } \\ \mathrm{j} & \text { Injection conditions } \\ \mathrm{s} & \text { Separation } \\ \mathrm{t} & \text { Throat of the nozzle } \\ 0 & \text { Stagnation Conditions } \\ 1 & \text { Flow condition downstream of the shock }\end{array}$

Abbreviations:

$N P R \quad$ "Nozzle Pressure Ratio" Pressure $=\mathrm{P}_{\mathrm{oi}} / \mathrm{p}_{\mathrm{a}}$.

SPR "Secondary Pressure Ratio" $=\mathrm{P}_{\mathrm{oj}} / \mathrm{P}_{\mathrm{oi}}$.

SVC "ShockVector Control" principle of injection in the divergent.

CN "Conical Nozzle." 


\section{Modeling the Fluidic Thrust Vectoring for Reacting Supersonic Nozzle Flow}

An analytical model for fluidic thrust vectoring in supersonic nozzle has been proposed by Sellam et al (2012). The model was built on the basis of the blunt body theory developed by Spaid and Zukoski (1968). The main feature of this model is based on the determination of the penetration height $h$ of the fluid injected into the main flow of the nozzle. This height depends both on the geometrical characteristics of the injection pore and those of the primary and secondary flow. For simplicity reasons, the interface between the main and the injected flows is assumed to be a quarter of sphere followed by an axisymmetric half open cylinder (Sellam et al., 2015).

The radius $h$ for this sphere is considered as an equivalent parameter to the height of a rising step (Sellam et al., 2015; Spaid \& Zukoski, 1968). The calculation of the fluidic height requires determining beforehand the force balance applied on the control volume which is delimited by the interface between the main and injected flows and the nozzle wall, in the $\mathrm{x}$ direction. This force balance is calculated by integrating the pressure forces using the modified Newton law (Sellam et al., 2015).

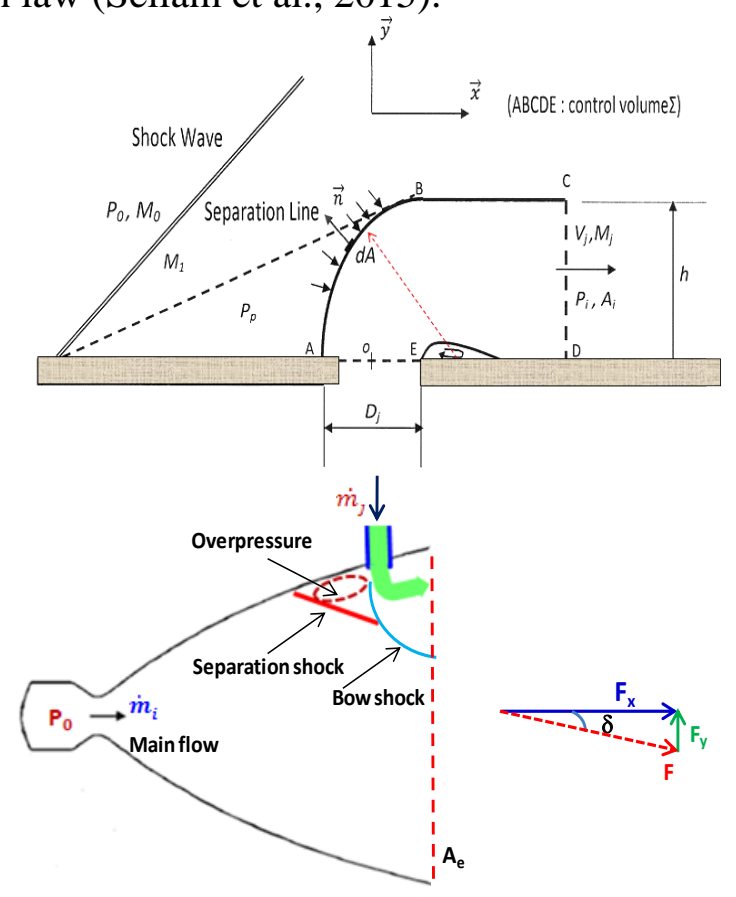

Figure1. Principle of thrust vectoring by fluidic injection (Sellam et al., 2015).

From the momentum equation and by using the isentropic flow relations, we obtain the equation below which determines the height of the equivalent fluidic step $h$. 


$$
h=D_{j}\left[\frac{C_{d} \gamma_{j}\left(\frac{2}{\gamma_{j}+1}\right)^{\frac{1}{\gamma_{j}-1}}\left[\frac{1}{\gamma_{j}^{2}-1}\left(\frac{p_{j}}{P_{0 j}}\right)^{\frac{\gamma_{j}-1}{\gamma_{j}}}\right]^{0.5}}{\left(p_{0}-p_{i}\right)+\frac{q_{0} C_{p \max }}{2}}\right]^{0.5}
$$

In this relation $P_{0 j}, \mathrm{p}_{\mathrm{i}}, \gamma_{\mathrm{j}}$ denote the injected total pressure, the static pressure at the exit of the control volume and the specific heat ratio of the injected flow, respectively. $D_{j}$ an $C_{d}$ are respectively the injection hole's diameter and the discharge coefficient. Subscripts $i$ and $j$ refer to the main and secondary flow respectively at the injection position.

The calculation of the separation line of the flow at the nozzle wall, upstream the injection pore, are obtained from both relations giving the height of the equivalent step and the Billig's formulas (Billig, 1967). The plateau pressure, for its part, is determined by means of the separation criteria, which express the value of $p_{p}$ as a function of the Mach number at the separation point, and the main flow conditions (Bloomer, Antl, \& Renas, 1961; Campbell \& Farley, 1960; Chapman, Huehn, \& Larson, 1958; Green, 1953; Kalt \& Badal, 1965; Reshotko \& Tucker, 1955; Schilling, 1962; Schmucker, 1973; Summerfield, Foster, \& Swan, 1954; Zukoski, 1967.

The flow reattachment position at the nozzle wall, downstream of the injection port is calculated using an empirical criterion given in reference (Mangin, 2012).

The thrust vector angle, it is then defined from the following equation.

$$
\delta=\tan ^{-1}\left[\frac{\sum F_{y}+\sum(\dot{m} V)_{y}}{\sum F_{x}+\sum(\dot{m} V)_{x}}\right]
$$

Where $\Sigma F_{x}, \Sigma F_{y}, \quad \sum(\dot{m} V)_{x}$ and $\sum(\dot{m} V)_{y}$ represent all pressure forces and momentums fluxes acting along $\mathrm{x}$ and $\mathrm{y}$ directions respectively.

The analytical model described above has been modified by introducing the thermochemical effects of reactive flows, in the evaluation of the fluidic thrust vectorization performance. This modification will allow the model to apply to operating conditions closer to that of a real rocket engine. The approach is based on the calculation of the chemical composition, the flow parameters in the combustion chamber, the nozzle throat and at all points of supersonic nozzle section. For this purpose, we consider that the rocket nozzle is supplied by $\mathrm{LH}_{2}$ and $\mathrm{LO}_{2}$ mixture with oxidizer/fuel mass flow ratio 
of 5.9 at combustion chamber pressure of 3 bars. The chemical reaction mechanism consists of eight chemical reactions that describe the dissociation/recombination involving 6 chemical species: $\mathrm{O} 2, \mathrm{H}_{2}, \mathrm{OH}, \mathrm{H}_{2} \mathrm{O}$, $\mathrm{O}$, and $\mathrm{H}$.

The chemical composition calculation described in this study is obtained by solving the species continuity equations (3).

$$
\omega_{s}=\frac{d C_{s}}{d t}
$$

Where $C_{s}$ is the molar concentration of the species $s$ and $\omega_{s}$ is the species production rates. Each reaction set has the general form (4).

$$
\sum_{s=1}^{N s} v_{s}^{\prime} Z_{s} \leftrightarrow \sum_{s=1}^{N s} v_{s}^{\prime \prime} Z_{s}
$$

Where $Z_{s}$ are the chemical symbols and $v^{\prime}, v^{\prime \prime}$ are the reactant and product stoichiometric coefficient respectively. Total species production rates $\omega_{s}$, are determined by summing the contributions from each reaction, and is given by the formula (5).

$$
\omega_{s}=k^{\prime} \prod_{s} C_{s}^{v_{s}^{\prime}}-k^{\prime \prime} \prod_{s} C_{s}^{v_{s}^{\prime \prime}}
$$

Where $k^{\prime}, k^{\prime \prime}$ are forward and backward reaction rates respectively, they are approximated by the Arrhenius law given by the formula (6) (Davidenko, Gökalp, Duffour, \& Magre, 2006).

$$
k=A T^{B} \exp (E / T)
$$

The coefficients A, B and E are summarized in Table 1.

By discretizing the equation (3) using the finite difference method, we obtain:

$$
\left(C_{s}\right)^{t_{i+1}}=\left(C_{s}\right)^{t_{i}}+\Delta t . \omega_{s}
$$

Using this new calculated value of $C_{s}$, we calculate the molar fractions $X_{s}$.

$$
X_{s}=\frac{C_{s}}{C_{m}}
$$

Where $C_{m}$ is the total concentration of the mixture, calculated as follows. 


$$
C_{m}=\sum_{s=1}^{N s} C_{s}
$$

The mass fractions $Y_{s}$ are given by:

$$
Y_{s}=X_{s} \frac{M_{s}}{M_{m}}
$$

With $M_{s}$ is the molar mass of the species $s$, and $M_{m}$ is the molar mass of the mixture expressed by:

$$
M_{m}=\sum_{s=1}^{N s} X_{s} \cdot M_{s}
$$

Table 1

Hydrogen and Oxygen Combustion Reaction Model

\begin{tabular}{|c|c|c|c|c|c|c|}
\cline { 2 - 8 } \multicolumn{1}{c|}{} & \multicolumn{3}{c|}{ Forward reaction rate } & \multicolumn{3}{c|}{ Backward reaction rate } \\
\hline Reaction & $\begin{array}{c}\text { A } \\
\text { (mol.cm.s) }\end{array}$ & B & E (K) & $\begin{array}{c}\text { A } \\
\text { (mol.cm.s) }\end{array}$ & B & E (K) \\
\hline $\mathrm{H}_{2}+\mathrm{O}_{2} \leftrightarrow 2 \mathrm{OH}$ & $1.70010^{13}$ & 0.0 & 24044 & $4.03210^{10}$ & 0.317 & 14554 \\
\hline $\mathrm{H}+\mathrm{O}_{2} \leftrightarrow \mathrm{OH}+\mathrm{O}$ & $1.98710^{14}$ & 0.0 & 8456 & $8.93010^{11}$ & 0.338 & -118 \\
\hline $\mathrm{H}_{2}+\mathrm{OH} \leftrightarrow \mathrm{H}_{2} \mathrm{O}+\mathrm{H}$ & $1.02410^{8}$ & 1.6 & 1660 & $7.96410^{8}$ & 1.528 & 9300 \\
\hline $\mathrm{H}_{2}+\mathrm{O} \leftrightarrow \mathrm{OH}+\mathrm{H}$ & $5.11910^{4}$ & 2.67 & 3163 & $2.70110^{4}$ & 2.649 & 2240 \\
\hline $2 \mathrm{OH} \leftrightarrow \mathrm{H}_{2} \mathrm{O}+\mathrm{O}$ & $1.50610^{9}$ & 1.14 & 50 & $2.22010^{10}$ & 1.089 & 8613 \\
\hline $\mathrm{H}+\mathrm{OH}+\mathrm{M} \leftrightarrow \mathrm{H}_{2} \mathrm{O}+\mathrm{M}$ & $2.21210^{22}$ & -2.0 & 0 & $8.93610^{22}$ & -1.835 & 59743 \\
\hline $2 \mathrm{H}+\mathrm{M} \leftrightarrow \mathrm{H}_{2}+\mathrm{M}$ & $9.79110^{16}$ & -0.6 & 0 & $5.08610^{16}$ & -0.362 & 52105 \\
\hline
\end{tabular}

Note: From Davidenko et al. (2006).

The thermochemical parameters of the flow in the combustion chamber, the throat and the nozzle are determined beforehand and compared to the CEA code (Gordon \& McBride, 1996).

The calculated molar fractions of the chemical species at the temperature of the combustion chamber $\left(\mathrm{T}_{\mathrm{c}}=3109.07^{\circ} \mathrm{k}\right)$ are shown in Table 2. The results are consistent with those given by the CEA Code. 
Table 2

Values of the Molar Fractions for Different Chemical Species

\begin{tabular}{|c|c|c|}
\hline $\begin{array}{c}\text { Chemical } \\
\text { species }\end{array}$ & $\begin{array}{c}\text { Calculated } \\
\text { Molar fractions }\end{array}$ & $\begin{array}{c}\text { CEA } \\
\text { Code }\end{array}$ \\
\hline $\mathrm{O}_{2}$ & 0.00797 & 0.00749 \\
\hline $\mathrm{H}_{2}$ & 0.25739 & 0.25725 \\
\hline $\mathrm{OH}$ & 0.05648 & 0.05851 \\
\hline $\mathrm{H}_{2} \mathrm{O}$ & 0.60537 & 0.60464 \\
\hline $\mathrm{O}$ & 0.00846 & 0.00811 \\
\hline $\mathrm{H}$ & 0.06431 & 0.06399 \\
\hline
\end{tabular}

Therefore, the various parameters of the combustion chamber, especially the specific heat at constant pressure, the entropy and the enthalpy of the frozen mixture, can be calculated using equations 12 to 18 (Gordon \& McBride, 1996).

The equations below (12-14) represent the specific heat at constant pressure, the enthalpy and the entropy of the mixture.

$$
\begin{gathered}
C_{P}=\sum_{i=1}^{n s} n_{i} C_{p_{i}}^{o} \\
H=\sum_{i=1}^{n s} n_{i} H_{i}^{o} \\
S=\sum_{i=1}^{n s} n_{i} S_{i}
\end{gathered}
$$

With:

$$
S_{i}=S_{i}^{o}-R \ln \frac{n_{i}}{n}-R \ln P
$$

Where:

$n_{i}$ is the number of moles of each species $i$ of the mixture:

$$
n=\sum_{i=1}^{n s} n_{i}
$$

The thermodynamic parameters of each species are given by the polynomial formulations given below (Gordon \& McBride, 1994):

$$
\frac{C_{p}^{o}}{R}=a_{1} T^{-2}+a_{2} T^{-1}+a_{3}+a_{4} T+a_{5} T^{2}+a_{6} T^{3}+a_{7} T^{4}
$$




$$
\begin{aligned}
& \frac{H^{o}}{R T}=-a_{1} T^{-2}+a_{2} T^{-1} \ln T+a_{3}+a_{4} \frac{T}{2}+a_{5} \frac{T^{2}}{3}+a_{6} \frac{T^{3}}{4}+a_{7} \frac{T^{4}}{5}+\frac{a_{8}}{T} \\
& \frac{S^{o}}{R}=-a_{1} \frac{T^{-2}}{2}-a_{2} T^{-1}+a_{3} \ln T+a_{4} T+a_{5} \frac{T^{2}}{2}+a_{6} \frac{T^{3}}{3}+a_{7} \frac{T^{4}}{4}+a_{9}
\end{aligned}
$$

The polynomial coefficients of the thermodynamic quantities $a_{1}, a_{2}, a_{3}, a_{4}$, $a_{5}, a_{6}, a_{7}, a_{8}, a_{9}$ are taken from reference (Gordon $\&$ McBride, 1994).

The calculation of the thermodynamic flow parameters at the nozzle throat is made possible, once the thermodynamic gas properties within the combustion chamber have been first determined, by assuming an isentropic expansion from the combustion chamber for frozen mixture. The calculation of temperature and pressure is based on iterative procedures.

For the temperature, the first estimate is given by equation (19), the other iterations are obtained by equation (20):

$$
\begin{gathered}
T_{t}=\frac{2 T_{0}}{\gamma_{0}+1} \\
\left(\ln T_{t}\right)_{\mathrm{i}+1}=\left(\ln T_{t}\right)_{\mathrm{i}}+\frac{S_{0}-S_{i}}{C_{p_{i}}}
\end{gathered}
$$

The iterative procedure is suspended as soon as the conservation condition of the entropy (21) is satisfied.

$$
\frac{S_{0}-S_{i}}{C_{p_{i}}}<0.510^{-4}
$$

A similar approach is adopted for the pressure calculation. Its first estimate is given by equation (22), the other iterations are obtained by equation (23). The iterative procedure is stopped if the flow conservation condition (24) is satisfied.

$$
\frac{P_{0}}{P_{t}}=\left(\frac{\gamma_{0}+1}{2}\right)^{\gamma_{0} /\left(\gamma_{0}-1\right)}
$$




$$
\begin{gathered}
\left(P_{t}\right)_{i+1}=\left(P \frac{1+\gamma_{0} M^{2}}{1+\gamma_{0}}\right)_{t, k} \\
\left|\frac{u_{e}^{2}-a_{e}^{2}}{u_{e}^{2}}\right| \leq 0.410^{-4}
\end{gathered}
$$

The same approach is followed for the calculation of the flow parameters within the different sections of the divergent portion of the nozzle. The estimation of the temperature is given by equation (25) and for the other iterations; equation (26) is used with $\mathrm{M}>1$.

$$
\begin{gathered}
T_{e}=\frac{T_{0}}{1+\left(\frac{\gamma_{t}-1}{2}\right) \times 2^{2}} \\
\left(\ln T_{t}\right)_{\mathrm{i}+1}=\left(\ln T_{t}\right)_{\mathrm{i}}+\frac{S_{0}-S_{i}}{C_{p_{i}}}
\end{gathered}
$$

The convergence of the iterative computations is obtained when the condition (27) is reached.

$$
\frac{S_{0}-S_{i}}{C_{p_{i}}}<0.510^{-4}
$$

The first estimate of the pressure is given by the empirical relations below (28-29), for different values of the section ratio. The other iterations are obtained by equation (30).

$$
\begin{gathered}
1<\frac{\mathrm{A}_{\mathrm{e}}}{\mathrm{A}_{\mathrm{t}}}<2 \\
\ln \frac{P_{0}}{P_{\mathrm{t}}}=\ln \frac{P_{0}}{P_{t}}+\sqrt{3.294\left(\ln \frac{A_{e}}{A_{t}}\right)^{2}+1.535 \ln \frac{A_{e}}{A_{t}}} \\
\frac{\mathrm{A}_{\mathrm{e}}}{\mathrm{A}_{\mathrm{t}}} \geq 2
\end{gathered}
$$




$$
\begin{gathered}
\ln \frac{P_{0}}{P_{\mathrm{t}}}=\gamma_{0}+1.4 \ln \frac{A_{e}}{A_{t}} \\
\left(\ln \frac{P_{0}}{P_{e}}\right)_{\mathrm{i}+1}=\left(\ln \frac{P_{0}}{P_{e}}\right)_{\mathrm{i}}+\left(\frac{\gamma_{0} u_{e}^{2}}{u_{e}^{2}-a_{e}^{2}}\right)\left[\ln \frac{A_{e}}{A_{t}}-\left(\frac{P_{t} u_{t}}{T_{t}}\right)\left(\frac{T_{e}}{P_{e} u_{e}}\right)\right]
\end{gathered}
$$

When condition (31) is satisfied, the iterative procedure is suspended.

$$
\left(\ln \frac{P_{0}}{P_{e}}\right)_{\mathrm{i}}-\left(\ln \frac{P_{0}}{P_{e}}\right)_{\mathrm{i}-1} \mid<0.410^{-5}
$$

After determining the evolution of the temperature and pressure at any section of the nozzle, we will then focus on the various parameters of the flow such as: Mach number, density and the specific heats ratio $\gamma$.

Table 3 below gives a comparison of the thermodynamic parameters at different sections of the conical nozzle, described below, obtained by the developed numerical tool and those from the CEA code. It's quite clear that the results totally comply with those of the CEA code.

Table 3

Values of the Thermodynamic Parameters for Different Divergent Sections of the Nozzle

\begin{tabular}{|c|l|l|l|l|l|l|}
\hline \multicolumn{2}{|c|}{$\mathrm{X}(\mathrm{m})$} & 0.000 & 0.025 & 0.050 & 0.075 & 0.108 \\
\hline \multirow{3}{*}{ Mach } & This work & 0.999 & 1.809 & 2.155 & 2.415 & 2.693 \\
\cline { 2 - 7 } & CEA Code & 1.000 & 1.811 & 2.155 & 2.415 & 2.692 \\
\hline \multirow{2}{*}{$\mathrm{P} / \mathrm{P}_{0}$} & This work & 0.561 & 0.180 & 0.099 & 0.062 & 0.037 \\
\cline { 2 - 7 } & CEA Code & 0.561 & 0.179 & 0.100 & 0.062 & 0.038 \\
\hline \multirow{2}{*}{$\rho / \rho_{0}$} & This work & 0.621 & 0.244 & 0.151 & 0.103 & 0.068 \\
\cline { 2 - 7 } & CEA Code & 0.621 & 0.243 & 0.151 & 0.103 & 0.069 \\
\hline \multirow{2}{*}{$\mathrm{T} / \mathrm{T}_{0}$} & This work & 0.904 & 0.737 & 0.661 & 0.605 & 0.548 \\
\cline { 2 - 7 } & CEA Code & 0.904 & 0.737 & 0.661 & 0.605 & 0.548 \\
\hline$\gamma$ & This work & 1.213 & 1.224 & 1.231 & 1.238 & 1.245 \\
\cline { 2 - 7 } & CEA Code & 1.213 & 1.224 & 1.231 & 1.238 & 1.245 \\
\hline
\end{tabular}

Figures 2 and 3, respectively, depict the variation of the specific heat $C_{p}(T)$ and the specific heat ratio $\gamma(T)$ of the reacting high temperature flow compared to constant $C_{p}$ and constant $\gamma$ for air perfect gas. The difference between these values is due to the large gap between the molar masse in both cases. This must have necessarily an influence on the thermodynamic parameters of the flow. 


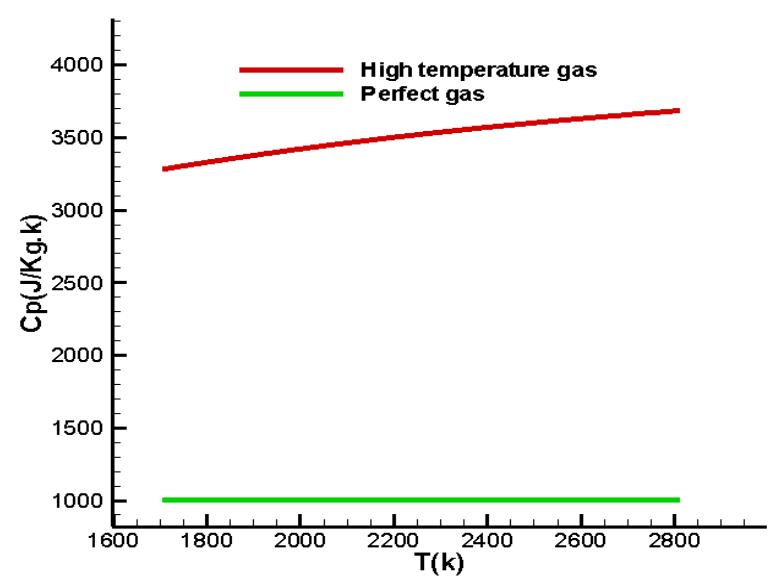

Figure 2. Variation of the specific heat for constant pressure for different values of the temperature.

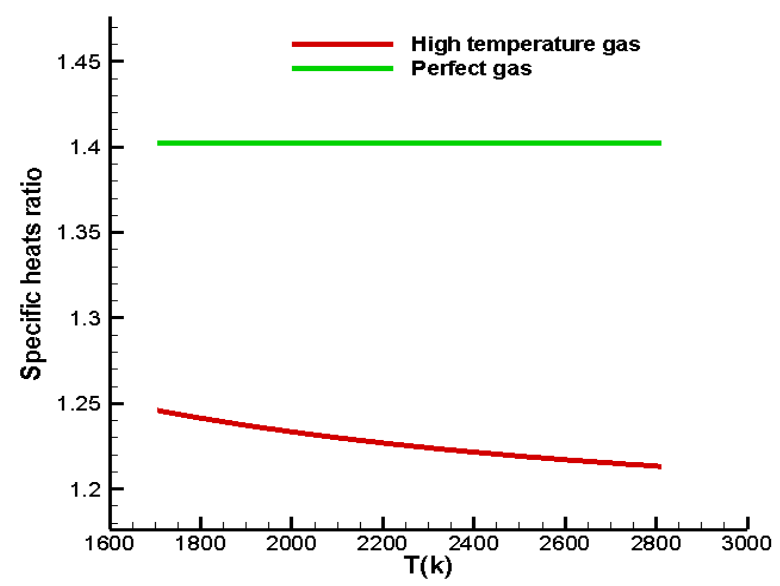

Figure 3. Variation of the specific heats ratio for different values of the temperature.

\section{Results and Discussions}

A computational program was built and developed in order to calculate the force balance along the $\mathrm{x}$ and y directions, the angle of deflection $\delta$ and the distribution of the pressure along the nozzle wall. It offers the possibility to choose different separation criterion when calculating the separation position $x_{s}$ and the plateau pressure $P_{p}$. It also permits to choose the desired $N P R, S P R$ and the position of the injector.

Two sets of axisymmetric nozzle configuration were used in this work: A conical CD nozzle and truncated ideal contour (TIC) nozzle. Both nozzles are designed to produce an exit flow at $M_{e}=3$ for the nozzle pressure ratio $N P R=37.5$. 
The conical CD axisymmetric nozzle is designed with a divergent section geometry length $l_{n}=100 \mathrm{~mm}$, conic half-angle $\alpha=5.42^{\circ}$, a throat radius $R t h=9.72 \mathrm{~mm}$ and an expansion ratio $A_{e} / A_{t h}=4.237$.

The TIC nozzle was calculated using the method of characteristics (MOC) for a Mach design $M_{D}=3.3$ and truncated at exit section Mach $M_{e}=$ 3.03 with an exit angle of $4.55^{\circ}$. The expansion ratio $A_{e} / A_{t h}$ is 4.87 with a throat radius $R_{t h}=10 \mathrm{~mm}$. The injection position $x_{j}$ was such as $x_{j} / l_{n}=0.9$ for the conical nozzle and $x_{j} / l_{n}=0.88$ for the TIC nozzle. The basic design parameters of the tested nozzles are summarized in Table 4 below:

Table 4

Nozzles Design Parameters

\begin{tabular}{ccccc}
\hline Nozzle & $\begin{array}{l}R_{t h}, \\
m m\end{array}$ & $M_{e}$ & $l, m m$ & $x_{j} / l_{n}$ \\
\hline Conical & 9.72 & 3 & 100 & 0.9 \\
\hline TIC & 10 & 3.03 & 68 & 0.88 \\
\hline
\end{tabular}

\section{Validation of the Numerical Tool}

The presence of a fluidic obstacle in the divergent of the supersonic nozzle caused by a secondary injection leads to the separation of the incoming turbulent boundary layer. The separation length generally depends on the flow regime in the boundary-layer and found to be proportional to the height of the obstacle. The application of the force balance including the pressure forces in the separation zone and the momentum flow rate of the injected secondary fluid leads to a pitching moment about the injector.

As a first step, the numerical tool developed and exposed in this work has been tested and validated according to the experimental study carried out by Zmijanovic et al. (2013) for the case of a conical nozzle. Table 5 below shows the calculated vectoring angles $\delta$ according to the injection flow rates and the separation criterion (Bloomer et al. 1961; Campbell \& Farley, 1960; Chapman et al., 1958; Green, 1953; Kalt \& Badal, 1965; Reshotko \& Tucker, 1955; Schilling, 1962; Schmucker, 1973; Summerfield et al., 1954; Zukoski, 1967) at the adaptation NPR $=37.5$ for dried cold air. A comparison with the experimental results, cited above, is also shown. 
Table 5

Values of the Vectoring Angle $\delta$ for Different Values of Injection Rates

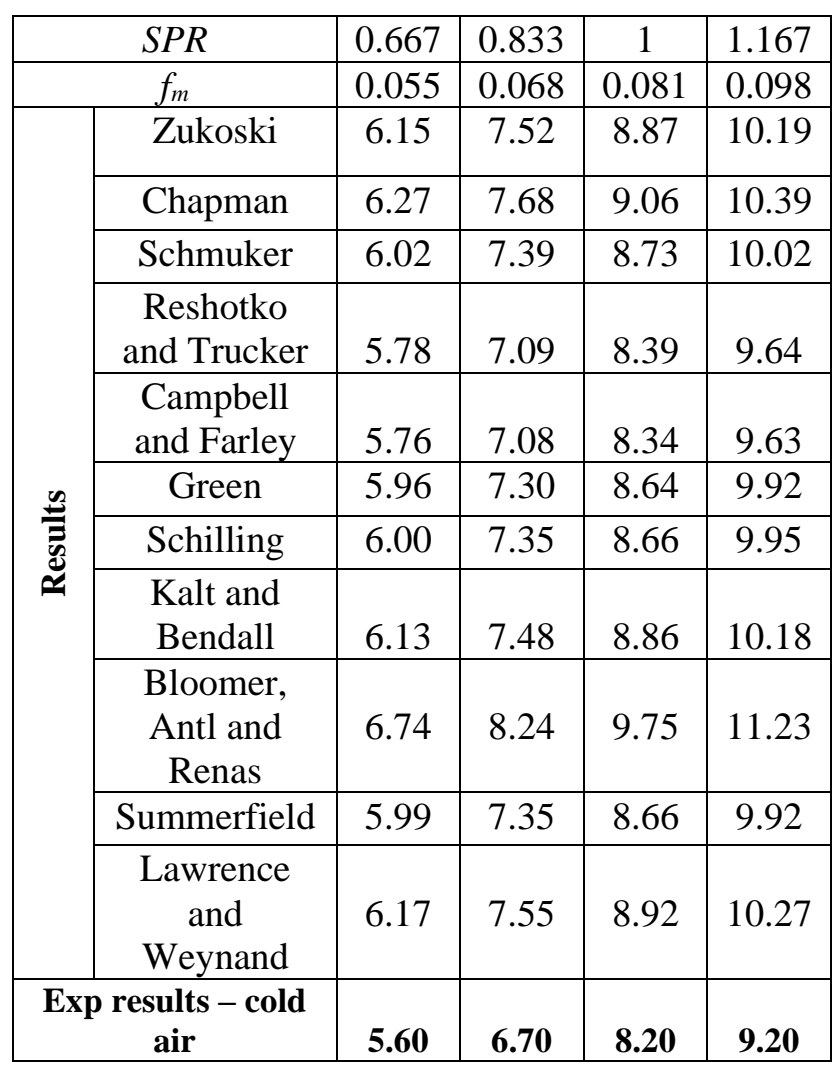

As it was observed in previous works Zmijanovic et al. (2013), we can notice that the vectoring angle $\delta$ linearly increases with increasing $S P R$ values. This results in both the increase of the separation area and the amount of the side force due to the momentum of the injected flow. We also notice that the choice of the separation criteria has some influence in the computation of the deviation angle and the best separation criteria are those mentioned in references (Campbell \& Farley, 1960; Green, 1953; Reshotko \& Tucker, 1955; Schilling, 1962), because these separation criteria are calibrated for the conical nozzles.

In Figure 4, we depict the influence of the separation criteria on the wall pressure distribution for operating nozzle at NPR $=37.5$ and $\mathrm{SPR}=1$, for cold perfect gas. The plateau pressure and the separation position are close to those obtained experimentally for cold air Zmijanovic et al. (2013) for the criteria mentioned in references (Campbell \& Farley, 1960; Green, 1953; Reshotko \& Tucker, 1955; Schilling, 1962), because these separation criteria are adapted for the conical nozzles.

The pressure is characterized by an isentropic expansion up to the separation position followed by a jump to the plateau pressure due to the boundary layer separation at the fluidic secondary injection obstacle. Behind 
the injector, we attend a depression caused by the reattachment of the flow at the wall of the nozzle.

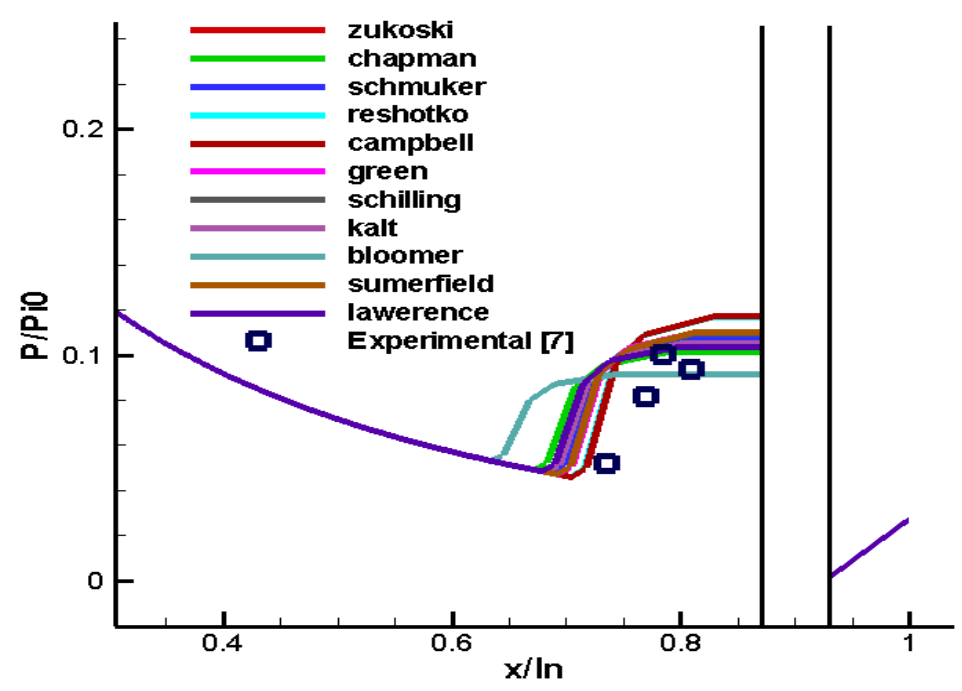

Figure 4. Pressure distribution at NPR $=37.5$ and $\mathrm{SPR}=1$, for cold perfect gas.

The influence of the injection position has also been studied. The experimental study, based on force balance measurements, has shown that injections close to the nozzle throat have proved ineffective and lead to relatively low performance in terms of vectorization (Zmijanovic, 2015). Analysis of the results obtained by means of CFD calculations, carried out during these same studies, showed that in terms of flow configuration generated by the transverse injection into the supersonic main flow nozzle, and taking into account the size of the nozzle used, the oblique shock resulting from this injection, is able to impact and to reflect from the opposite wall. This leads to generate a separation zone that works in the opposite direction of the vectorization, which explains the decrease in thrust vectoring angles. 


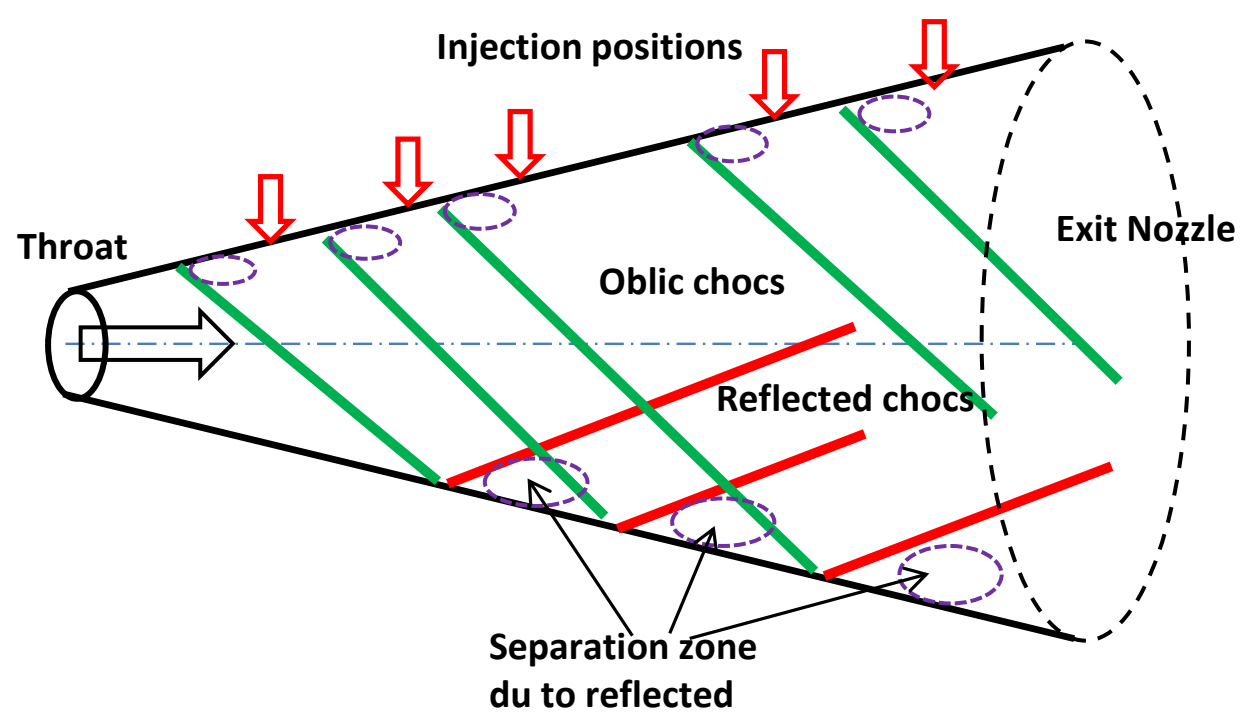

Figure 5. Schematic sketch of choc reflection phenomena resulting from fluidic injection in supersonic nozzle.

Calculated and measured thrust vectoring performance for several injector positions $\left(x_{j}\right)$, for cold perfect gas at $N P R=37.5, S P R=1$ and for different separation criteria are summarized in Table 6.

For the experimental results, as it was related above, the location of the secondary injection has a great influence on the vectoring performance. In fact, the force balance measurements revealed a large decrease in the vectorization angle as the injection is made closer to the nozzle throat.

In fact, the force balance measurements revealed a large decrease in the vectorization angle as the injection is made closer to the nozzle throat. However, our model, not including the phenomenon of reflection described previously, gives results far from the experiment. Nevertheless, it remains very close to the experience as soon as the injection is close to the exit. In this case, the decrease in the vectorization angle is solely related to the reduction of the contribution of the overpressure zone as the Mach number increases and the pressure in the nozzle decreases. Figure 6 depicts the comparison between these two results.

From these results, we will focus particularly, in the following, on the injections made only in the vicinity of the outlet section for the reactive flows. 
Table 6

Variation of the Vectoring Angle for Different Positions of the Injector

\begin{tabular}{|c|c|c|c|c|c|c|}
\hline \multicolumn{2}{|c|}{$\begin{array}{c}\text { Injection } \\
\text { position }\left(x_{j} / l_{n}\right)\end{array}$} & 0.7 & 0.75 & 0.8 & 0.9 & 0.95 \\
\hline \multirow{11}{*}{$\underset{\ddot{n}}{\ddot{E}}$} & Zukoski & 9.81 & 9.59 & 9.40 & 8.87 & 8.68 \\
\hline & Chapman & 10.04 & 9.83 & 9.61 & 9.06 & 8.85 \\
\hline & Schmuker & 9.70 & 9.51 & 9.27 & 8.73 & 8.54 \\
\hline & $\begin{array}{c}\text { Reshotko } \\
\text { and } \\
\text { Trucker }\end{array}$ & 9.29 & 9.11 & 8.88 & 8.39 & 8.20 \\
\hline & $\begin{array}{l}\text { Campbell } \\
\text { and Farley }\end{array}$ & 9.26 & 9.05 & 8.86 & 8.34 & 8.19 \\
\hline & Green & 9.63 & 9.42 & 9.19 & 8.64 & 8.45 \\
\hline & Schilling & 9.46 & 9.32 & 9.14 & 8.66 & 8.49 \\
\hline & $\begin{array}{l}\text { Kalt and } \\
\text { Bendall }\end{array}$ & 9.80 & 9.63 & 9.41 & 8.86 & 8.65 \\
\hline & $\begin{array}{c}\text { Bloomer, } \\
\text { Antl and } \\
\text { Renas }\end{array}$ & 11.04 & 10.74 & 10.46 & 9.75 & 9.49 \\
\hline & $\begin{array}{l}\text { Summerfi } \\
\text { eld }\end{array}$ & 9.26 & 9.16 & 9.05 & 8.66 & 8.50 \\
\hline & $\begin{array}{c}\text { Lawrence } \\
\text { and } \\
\text { Weynand }\end{array}$ & 9.98 & 9.76 & 9.51 & 8.92 & 8.71 \\
\hline \multicolumn{2}{|c|}{$\begin{array}{l}\text { Expe results - } \\
\text { cold air }\end{array}$} & 0.82 & 4.6 & 7.15 & 8.27 & 8.01 \\
\hline
\end{tabular}

Note: From Zmijanovic et al. (2015).

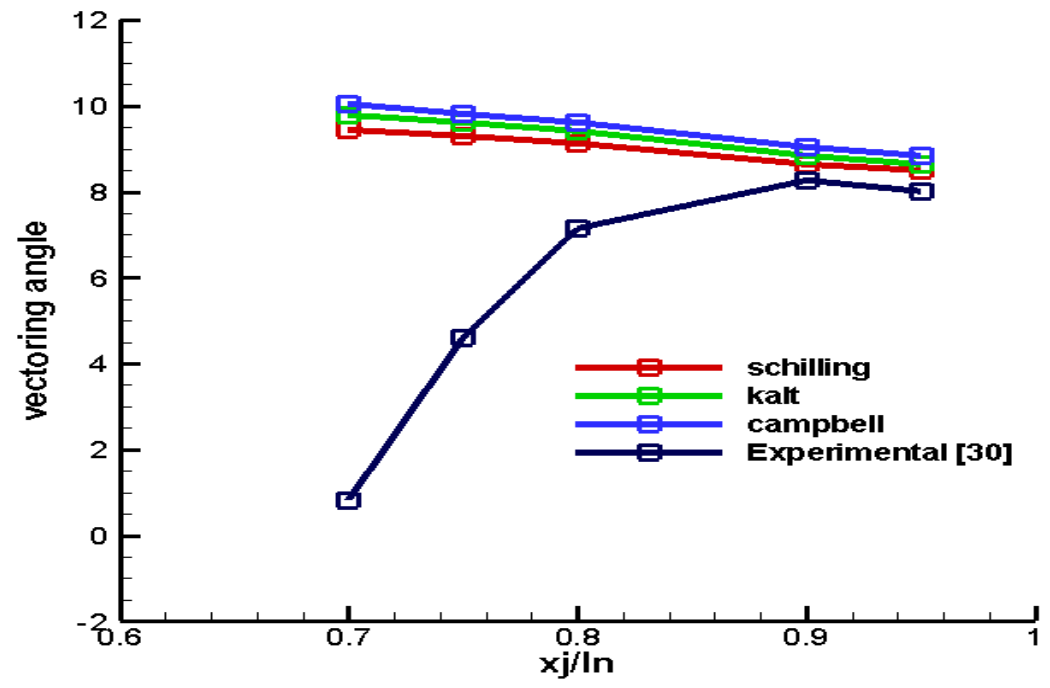

Figure 6. Evolution of the thrust vectoring with injection positions. 


\section{Fluidic Thrust Vectoring Performance in Reactive Flow Influence of the separation criteria.}

The analytical model developed in the previous work (Sellam et al., 2012, 2015) and validated for cold-air blowing nozzle, has been improved by taking into account the effects of chemical reactions, occurring in the nozzle flow, in the fluidic thrust vectoring performance.

The methodology used to calculate the fluidic thrust vectoring performance, for cold air, is followed hereafter in the case of reacting flow for both conical and TIC nozzles. After calculating the flow parameters, Mach number, pressure, temperature, density and specific heats ratio, for each point of the divergent part of the nozzle, considering the reactive mechanism described below, the fluidic thrust vectoring angle was computed and a comparison with the experimental data for cold flow is made.

The fluidic thrust vectoring was performed with a circular injection hole at $x_{j} / x_{t}=0.9$ for the conical nozzle and $x_{j} / x_{t}=0.88$ for the TIC nozzle. The results obtained concerning the fluidic thrust vectoring, are from the logical point of view identical to those of the first case (conical nozzle), that is to say all the curves have the same shape.

Table 7 below shows the vectoring angle $\delta$ for different separation criteria at $N P R=37.5$ and for the pressure ratio $(S P R=1)$. It is obvious that in this case the secondary to primary mass flow rates ratios $\left(f_{m}\right)$, rather than the height of penetration are not identical in the two cases. $f_{m}=0.081, h=8.05 \mathrm{~mm}$ for cold air and $f_{m}=0.042, h=7.87 \mathrm{~mm}$ for high temperature reacting flow.

Consequently, the calculated vectoring angle $\delta$ in case of the high temperature gas flow is less than the cold perfect gas one. This result is due, on the one hand, to the decrease of flow momentum at the injector and on the other hand to the decrease of the separation zone in front of the injector, as a consequence of the decrease of the fluidic obstacle height $h$, which strongly depends on $\gamma$.

We can also notice that the separation criteria have an influence on the calculation of the deflection angle. Indeed, all these empirical criteria have been adjusted for geometric configurations and specific flow conditions applied to each case.

In all cases, the numerical results show that the vectoring of the fluid thrust remains effective for high temperature reacting gas. 
Table 7

Vectoring Angle $\delta$ for NPR $=37.5, S P R=1$

\begin{tabular}{|c|c|c|c|c|c|}
\hline \multirow{2}{*}{\multicolumn{2}{|c|}{\begin{tabular}{|c|} 
Nozzle \\
Type of gas
\end{tabular}}} & \multicolumn{2}{|c|}{ Conical } & \multicolumn{2}{|c|}{ TIC } \\
\hline & & $\begin{array}{c}\text { Cold air } \\
\left(T_{0}=245\right) \\
\text { fm }=0.081\end{array}$ & $\begin{array}{c}\text { Reacting H2-O2 } \\
\text { gas }\left(\mathrm{T}_{0}=3109.07\right) \\
f m=0.042\end{array}$ & $\begin{array}{c}\text { Cold air } \\
\left(\mathrm{T}_{0}=\mathbf{2 4 5}\right) \\
\mathrm{fm}=\mathbf{0 . 0 7 6} \\
\end{array}$ & $\begin{array}{c}\text { Reacting H2-O2 } \\
\left(\mathrm{T}_{0}=3109.07\right) \\
f m=0.040\end{array}$ \\
\hline \multirow{8}{*}{ 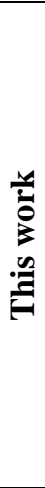 } & Chapman & 9.06 & 8.54 & 7.35 & 7.10 \\
\hline & $\begin{array}{c}\text { Reshotko and } \\
\text { Trucker }\end{array}$ & 8.39 & 7.82 & 7.06 & 6.60 \\
\hline & $\begin{array}{c}\text { Campbell and } \\
\text { Farley }\end{array}$ & 8.34 & 7.79 & 6.99 & 6.61 \\
\hline & Green & 8.64 & 8.16 & 7.16 & 6.81 \\
\hline & Schilling & 8.66 & 8.54 & 7.27 & 7.21 \\
\hline & $\begin{array}{l}\text { Bloomer, Antl } \\
\text { and Renas }\end{array}$ & 9.75 & 9.55 & 7.74 & 7.69 \\
\hline & Summerfield & 8.66 & 8.41 & 7.30 & 7.22 \\
\hline & $\begin{array}{c}\text { Lawrence and } \\
\text { Weynand }\end{array}$ & 8.92 & 8.54 & 7.37 & 7.08 \\
\hline \multicolumn{2}{|c|}{$\begin{array}{l}\text { Experimental } \\
\text { results - cold air }\end{array}$} & \multicolumn{2}{|r|}{8.27} & \multicolumn{2}{|c|}{6.78} \\
\hline
\end{tabular}

Figures 7 and 8 illustrates the pressure distribution for the two nozzles, calculated for cold air and reacting gas using the Schilling's (1962) criterion, compared to the experimental values given in reference (Zmijanovic et al., 2013, 2015) for NPR=37.5 and $\mathrm{SPR}=1$.

The calculated separation positions $\left(x_{s} / l_{n}\right)$, for the conical nozzle, are 0.72 and 0.73 for the cold perfect and high temperature gases respectively, while the experimental pressure investigations give the separation position at $x_{s} / l_{n}=0.74$, in the case with cold air Zmijanovic et al. (2013). The values of the pressure jump are also in good agreement for the cold air investigations, while the plateau pressure is higher in the case of the high temperature gas. In fact, it's well known that the boundary layer is thicker for high temperature flow and tends de separate more quickly due to the adverse pressure gradient. 


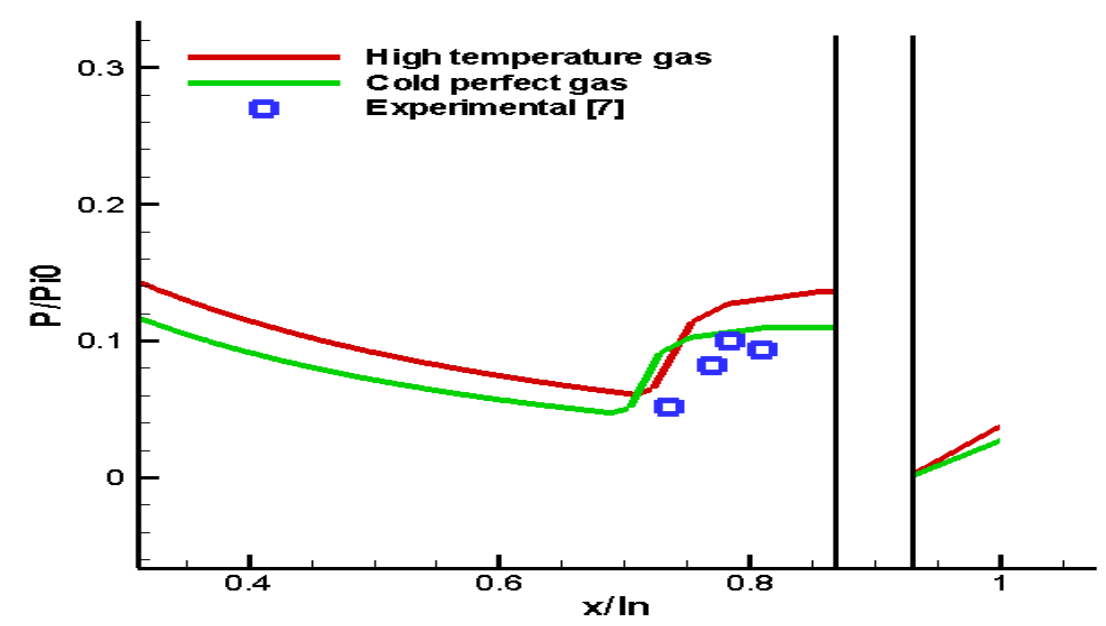

Figure 7. Wall pressure distribution of conical nozzle for NPR $=37.5$ and SPR $=1$.

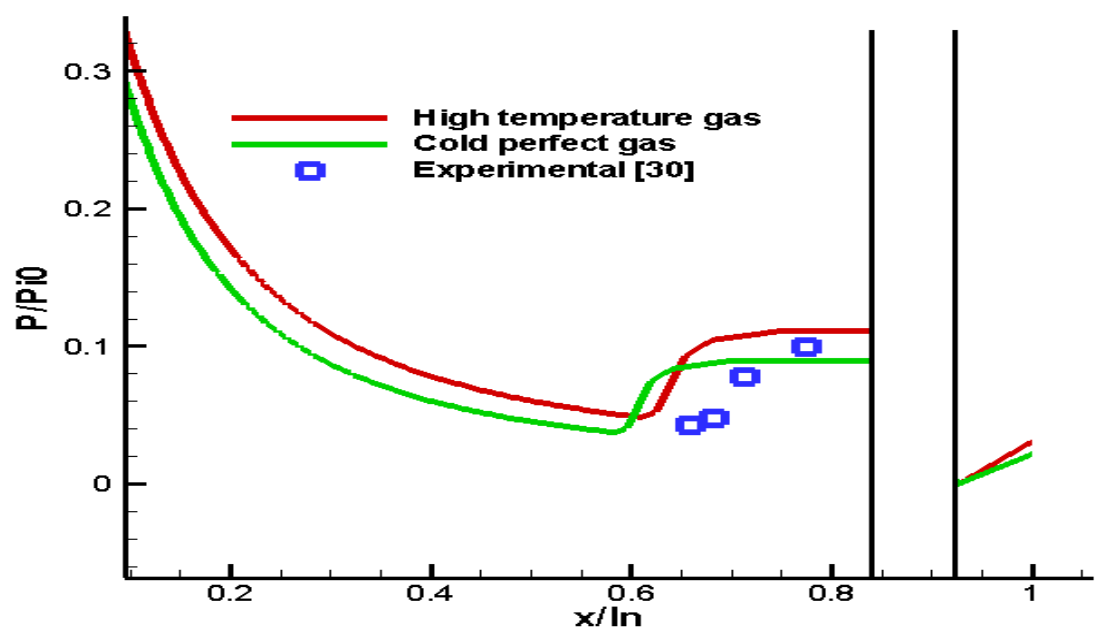

Figure 8. Wall pressure distribution of TIC nozzle for NPR $=37.5$ and SPR $=$ 1.

\section{Influence of the secondary injection pressure (SPR).}

Figure 9 shows the results of the theoretical model for high temperature gas, in terms of wall pressure to total pressure ratio upstream and downstream of the injector obtained for the adapted conditions of the experimentally tested nozzle Zmijanovic et al. (2013) for different injection flow rates, while the plateau pressure is computed with Schilling criterion. As it can be seen in this plot, and as it is expected, the separation distance increases with the rate of injected flow for an identical operating regime of the nozzle. Indeed, the fluidic obstacle height $h$ given by relation (1) also increases with the injection pressure ratio. 


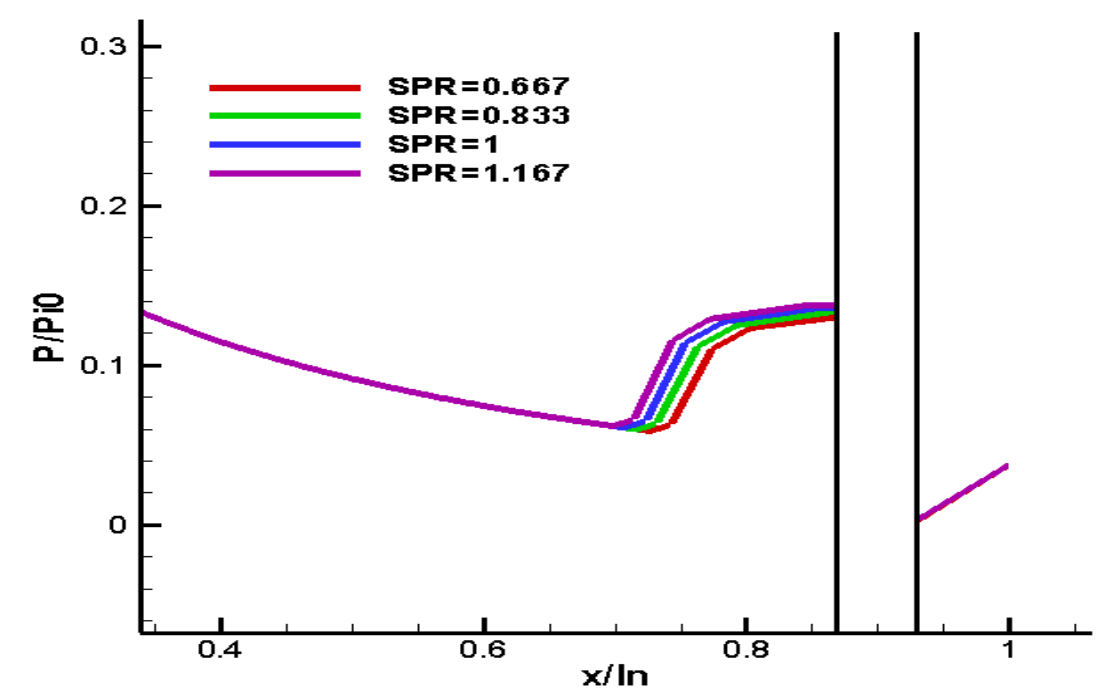

Figure 9. Wall pressure profile as function of injection rates.

Figure 10 illustrates the evolution of the vectoring angle $\delta$ according to the injection flow rates for operating nozzle at adaptation regime $(\mathrm{NPR}=37.5)$ for the two types of gas. The experimental data carried out for cold air are also depicted.

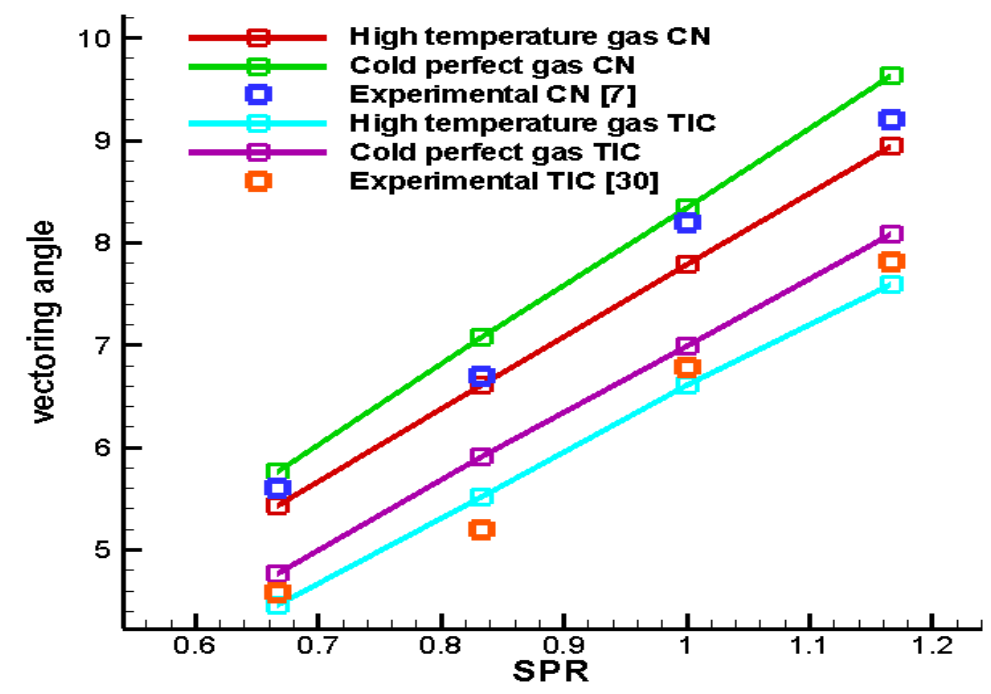

Figure 10. Variation of the vectoring angle $\delta$ according to SPR for different types of gas.

As we can see, in both nozzle configurations, the vectoring angle $\delta$ linearly increases with the increasing SPR. The maximum is reached for SPR $=1.167$. On the other hand, the influence of the thermochemical state of the 
gas on the calculation of the vectoring angle is well highlighted. As it was mentioned above, in all cases the performance of the fluidic thrust vectoring is affected by the thermodynamic properties of the flow field. Indeed, the specific heat ratio and molecular mass of the species have substantial impact on the penetration height, the main flow deflection and thus thrust vectoring performance.

\section{Conclusions}

In the presented study, the previous works conducted with cold perfect gas have been extended to high temperature gas investigations. It is found that the fluidic thrust vectoring remains well effective under all injection gas conditions. Major distinction is found concerning the difference of thermodynamic gas properties, as molecular mass and specific heat ratio and their influence on the generated thrust vectoring performance. It may be asserted that specific heat ratio, molecular mass and thus momentum of the injected gas have substantial impact on the penetration height, main flow deflection and thus on the thrust vectoring performance.

Fluidic thrust vectoring performance, obtained by the secondary injection in the nozzle divergent in the case of the reactive high temperature was compared with those obtained for cold air experiment. According to these results, the secondary injection has proved its ability to remain effectiveness in reactive flow.

Similarly, the results obtained show clearly that the high-pressure ratios and the injection positions that are closed to the outlet section of the nozzle are the most efficient. It also found that the thrust efficiency is about $1.2 \%$ of injected flow.

Finally, in terms of performance, this work has highlighted for the first time the importance of the thermochemical effects on fluidic thrust vectorization. The results are more than encouraging. This work provides a new impetus to continue experimental work with hot reactive flows for this purpose. 


\section{References}

Billig, F. S. (1967). Shock-wave shapes around spherical- and cylindricalnosed bodies. Journal of Spacecraft and Rockets, 4(6). https://doi.org/10.2514/3.28969

Bloomer, H., Antl, R., \& Renas, P. (1961, September). Experimental study of effects of geometric variables on performance of conical rocket engine exhaust nozzles. NASA Journal, 21(9). Retrieved from https://searchworks.stanford.edu/view/8605418

Campbell, C., \& Farley, J. (1960, September). Performance of several conical convergent-divergent rocket-type exhaust nozzles. NASA TN D-467. Retrieved from https://ntrs.nasa.gov/search.jsp?R=19980227347

Chapman, D. R., Huehn, D. M., \& Larson, H. K. (1958). Investigation of separated flows in supersonic and subsonic streams with emphasis on the effect of transition. Technical Report NACA TR 1356, NACA. Retrieved from https://ntrs.nasa.gov/search.jsp?R=19930092343

Davidenko, D. M., Gökalp, I., Duffour, E., \& Magre, P. (2006). Systematic numerical study of the supersonic combustion in an experimental combustion chamber. AIAA Paper 2006-7913. https://doi.org/10.2514/6.2006-7913

Deng, R., Kong, F., \& Kim, H. D. (2014). Numerical simulation of fluidique thrust vectoring in an axisymmetric supersonic nozzle. Journal of Mechanical Science and Technology. doi:10.1007/s12206-014-1119-x

Ferlauto, M., \& Marsilio, R. (2017). Numerical investigation of the dynamic characteristics of a dual-throat-nozzle for fluidic thrust-vectoring. AIAA Journal, 55(1). doi:10.2514/1.J055044

Flamm, J. D., Deere, K. A., Mason, M. L., Berrier, B. L., \& Johnson. S. K. (2007, July). Experimental study of an axisymmetric dual throat fluidic thrust vectoring nozzle for supersonic aircraft application. 43rd Joint Propulsion Conference \& Exhibit, Cincinnati, OH.

Gordon, S. F., \& McBride, B. J (1994). Computer program for calculation of complex chemical equilibrium compositions and applications. NASA RP-1311. Retrieved from https://ntrs.nasa.gov/archive/nasa/ casi.ntrs.nasa.gov/19780009781.pdf

Gordon, S. F., \& McBride, B. J (1996). Computer program for calculation of complex chemical equilibrium compositions and applications. NASA RP-1311, NASA Glenn Research Center. Retrieved from https://ntrs.nasa.gov/archive/nasa/casi.ntrs.nasa.gov/19780009781.pdf

Green, L. (1953, January-February). Flow separation in rocket nozzles. ARS Journal, 23(1). https://doi.org/10.2514/8.4536

Jerin, J., Subanesh, S. R., Tharika, R. K., Subanesh, S. R., \& Naveen, N. (2013). Numerical studies on thrust vectoring using shock induced supersonic secondary jet. International Journal of Mechanical, Aerospace, Industrial and Mechatronics Engineering, 7(8). 
Jun, Y. H., \& Hong. G. S. (2012). Fluidic thrust-vector control of supersonic jet using coflow injection. Journal of Propulsion and Power. https://doi.org/10.2514/1.B34266

Kalt, S., \& Badal, D. (1965, May). Conical rocket nozzle performance under flow separated conditions. Journal of Spacecraft and Rockets, 2(3). https://doi.org/10.2514/3.28200

Mangin, B., Chpoun, A., \& Jacquin, L. (2006). Experimental and numerical study of the fluidic thrust vectoring of a two-dimensional supersonic nozzle. AIAA Paper 2006-3666. https://doi.org/10.2514/6.2006-3666

Mnafeg, I., Abichou, A., \& Beji, L. (2015). Thrust vectoring control of supersonic flow through an orifice injector. International Journal of Mechanical, Aerospace, Industrial, Mechatronic and Manufacturing Engineering, 9(7). doi.org/10.5281/zenodo.1108705

Reshotko, E., \& Tucker, M. (1955). Effect of a discontinuity on turbulent boundary-layer thickness parameters with application to shock-induced separation. NACA TN 3454. Retrieved from http://citeseerx.ist.psu.edu/ viewdoc/summary?doi=10.1.1.462.8029

Schilling, M. (1962, June). Flow separation in a rocket nozzle (Master's thesis). Buffalo, NY: University of Buffalo.

Schmucker, R. H. (1973, November). Status of flow separation prediction in liquid propellant rocket nozzles. NASA TM X-64890. Retrieved from https://ntrs.nasa.gov/search.jsp?R=19750003989

Sellam, M., Chpoun, A., Zmijanovic, V., \& Lago V. (2012). Fluidic thrust vectoring of an axisymmetrical nozzle: An analytical model. International Journal of Aerodynamics, 2(2-4), 193-209. doi:10.1504/IJAD.2012.049112

Sellam, M., Zmijanovic, V., Leger, L., \& Chpoun A. (2015). Assessment of gas thermodynamic characteristics on fluidic thrust vectoring performances: Analytical, experimental and numerical study. International Journal of Heat and Fluid Flow, 53, 156-166. doi:10.1016/j.ijheatfluidflow.2015.03.005

Spaid, F. W., \& Zukoski, E. E. (1968). A study of the interaction of gaseous jets from transverse slots with supersonic external flows. AIAA Journal, 6. https://doi.org/10.2514/3.4479

Summerfield, M., Foster, C., \& Swan, W. (1954, September). Flow separation in overexpanded supersonic exhaust nozzles. Jet Propulsion, 24.

Van Pelt, H., Neely, A., \& Young, J. (2015, July 6-9). A system study on fluidic thrust vectoring. International space planes and hypersonic systems and technologies conferences, Glasgow, Scotland. doi:10.13140/RG.2.1.1710.1287

Zmijanovic, V., Lago, V., Leger, L., Depussay, E., Sellam, M., \& Chpoun, A. (2013). Thrust vectoring effects of a transverse gas injection into a supersonic cross flow of an axisymmetric convergent-divergent nozzle. 
Progress in Propulsion Physics, 4, 227-256. doi:10.1051/eucass/201304227

Zmijanovic, V., Lago, V., Sellam, M., \& Chpoun, A. (2013). Thrust shock vector control of an axisymmetric conical supersonic nozzle via secondary transverse gas injection. Shock Waves Journal, 24(1), 97-111. doi:10.1007/s00193-013-0479-y

Zmijanovic, V., Leger, L., Depussay, E., Sellam, M., \& Chpoun, A. (2015, October). Experimental-numerical parametric investigation of a rocket nozzle secondary injection thrust vectoring. Journal of Propulsion and Power. doi:10.2514/1.B35721

Zmijanovic, V., Leger, L., Lago, V., Sellam, M., \& Chpoun, A. (2012, July 30 -August 01). Experimental and numerical study of thrust-vectoring effects by transverse gas injection into a propulsive axisymmetric $C$-D nozzle. Number AIAA-2012-3874, AIAA paper-48th joint propulsion conference \& exhibit, Atlanta, Georgia.

Zukoski, E. E. (1967, October). Turbulent boundary-layer separation in front of a forward-facing step. AIAA Journal, 5(10). https://doi.org/10.2514/3.4299 